\title{
Canis, Konrad, Bismarcks Außenpolitik 1870-1890
}

\section{Stéphanie Burgaud}

\section{OpenEdition \\ Journals}

Édition électronique

URL : http://journals.openedition.org/ifha/2230

DOI : $10.4000 /$ ifha. 2230

ISSN : 2198-8943

Éditeur

IFRA - Institut franco-allemand (sciences historiques et sociales)

\section{Référence électronique}

Stéphanie Burgaud, «Canis, Konrad, Bismarcks Außenpolitik 1870-1890 », Revue de l'IFHA [En ligne], Date de recension, mis en ligne le 01 janvier 2010, consulté le 22 septembre 2020. URL : http:// journals.openedition.org/ifha/2230 ; DOI : https://doi.org/10.4000/ifha.2230

Ce document a été généré automatiquement le 22 septembre 2020.

(CIFHA 


\title{
Canis, Konrad, Bismarcks Außenpolitik 1870-1890
}

\author{
Stéphanie Burgaud
}

Le dernier ouvrage de K.C., Bismarcks Außenpolitik 1870-1890 (1ère édition, 2004) reprend le titre bien connu d'Andreas Hillgruber (1972, réédition en 1993) mais là s'arrête la comparaison. Certes l'auteur ne surprendra pas par son approche : la politique extérieure de l'Allemagne impériale se confond avec les intentions, les desseins, les calculs, les reculs de son fondateur et chancelier Bismarck. Et si les aspects économiques et sociaux prennent un peu plus de place au fil de l'analyse, cela ne remet pas en cause la méthode classique de l'auteur. Traditionnel aussi le plan chronologique en trois moments : 1870-1879 (naissance du Reich et d'une situation "semihégémonique ») ; 1879-1885 (temps d'une relative sécurité) ; 1885-1890 (période où les crises s'accumulent suscitant des expédients peu satisfaisants). L'originalité de l'auteur n'est pas davantage dans l'utilisation de concepts plus ou moins complexes. Il ne semble d'ailleurs pas au premier abord formuler explicitement de nouvelle thèse sur la diplomatie bismarckienne.

Pourtant, au terme de la lecture, le résultat est conforme à la ligne directrice annoncée en introduction : après avoir étudié la politique extérieure de l'Allemagne entre 1890 et 1902 (K. Canis, Von Bismarck zur Weltpolitik. Deutsche Außenpolitik 1890 bis 1902, Berlin, 1997), l'auteur souhaitait explorer les décennies antérieures. La problématique est placée sous le signe de la continuité. Et il y a bien des éléments de l'ère bismarckienne, mis au jour ici, que l'on retrouvera par la suite : par exemple une diplomatie couronnée de succès comme assise politique pour dominer et régner sans partage à l'intérieur (p. 131). L'analyse de deux décennies de politique extérieure dresse aussi un portrait assez inédit parmi les spécialistes allemands du genre. La diplomatie bismarckienne n'est que manipulations, pressions, menaces d'où ce sinistre constat qu'elle ne peut permettre d'obtenir de fidèles alliés («Vertrauen zu erwecken vermochte sie nicht, in Russland nicht, in Frankreich ohnehin nicht, aber auch nicht mehr in Österreich-Ungarn (...) », p. 274). Ainsi l'isolement croissant que connaîtra le Reich au tournant des deux siècles est déjà en germe. De même, l'instabilité de la situation diplomatique de l'Allemagne en Europe n'est pas le fruit des errements de 
successeurs peu doués ; elle est héritée. Bismarck n'a jamais fondé d'équilibre de sécurité. Non que K.C. y accuse le bellicisme du Chancelier : l'existence même de l'Empire explique l'hostilité de l'Europe à laquelle Bismarck n'aurait donc pas répondu par une stratégie défensive après 1875 , mais constamment par l'offensive et à grande échelle si l'on suit l'auteur. La mission Radowitz de 1875 devait aboutir à un partage de l'Europe : l'Ouest à l'Allemagne, l'Est à la Russie tsariste. La méfiance de cette dernière, l'alliance autrichienne de 1879, en fondant un bloc germanique menaçant en Europe centrale, devait la faire céder. Mais l'alliance des Trois Empereurs de 1881 n'a rien à voir avec ces ambitions d'origine que le chancelier n'abdiquerait pas. La « double crise " de 1885 (à l'Est avec l'affaire bulgare, à l'Ouest avec le boulangisme) serait une occasion de les réaliser. Avortées, elles restent cependant difficiles à prouver indubitablement comme souvent les actions du jeu bismarckien.

Qu'importe ; le schéma général brossé dans l'ouvrage : une stratégie offensive assise sur la manipulation des adversaires - comme des alliés de circonstances - et sur la guerre, repose sur une utilisation convaincante des archives. Il est aussi cohérent avec ce que ces dernières nous ont appris de la décennie antérieure (S. Burgaud, La politique russe de Bismarck et l'unification allemande. Mythe fondateur et réalités politiques, Strasbourg, 2010) et qui mériterait ici d'être davantage utilisé (voir les éternels poncifs relayés p. 29), surtout lorsque l'on explore les continuités de cette histoire...

Stéphanie Burgaud (IEP de Toulouse) 